\title{
UJI KOMPOSISI KIMIA KOMPOS Azolla mycrophylla DAN PUPUK ORGANIK CAIR (POC) Azolla mycrophylla
}

\author{
SRI UTAMI LESTARI ${ }^{1}$ *, ENNY MUTRYARNY ${ }^{2}$, NENG SUSI $^{3}$ \\ Prodi Agroteknologi Fakultas Pertanian Universitas Lancang Kuning \\ Email : uut76solo@gmail.com Telp.085364680005
}

\begin{abstract}
ABSTRAK
Tujuan penelitian untuk mendapatkan komposisi kimia kompos dan POC Azolla mycrophylla. Penelitian dilakukan secara eksperimen dengan tahapan awal pembuatan kompos dan POC Azolla mycrophylla setelah itu dilakukan analisis laboratorium terhadap komposisi kimianya. Analisis data dilakukan dengan menggunakan analisis sekriptif kualitatif berdasarkan hasil uji laboratorium terhadap komposisi kimia kompos berbahan dasar azolla. Hasil penelitian disimpulkan bahwa hasil analisis kimia kompos dan POC Azolla mycrophylla menunjukkan bahwa kandungan hara kompos Azolla mycrophylla lebih tinggi dibandingkan dengan POC Azolla mycrophylla. Hasil analisis kompos Azolla mycrophylla dan POC Azolla mycrophylla telah memenuhi standard pupuk organik menurut Permentan No.28 tahun 2009.
\end{abstract}

Kata Kunci : Kompos, POC, Azolla

ABSTRACT

The aim of the study was to obtain the chemical composition of compost and POC Azolla mycrophylla. The study was conducted experimentally with the initial stages of composting and POC Azolla mycrophylla after which laboratory analysis of its chemical composition was carried out. Data analysis was carried out using qualitative descriptive analysis based on the results of laboratory tests on the chemical composition of Azolla-based compost. The results of the study concluded that the results of chemical analysis of compost and POC Azolla mycrophylla showed that the content of Azolla mycrophylla compost was higher than that of the Azolla mycrophylla POC. The results of the compost analysis of Azolla mycrophylla and Azolla mycrophylla POC have met the standards of organic fertilizer according to Minister of Agriculture No.28 of 2009.

Keywords: Compost, POC, Azolla

Diterima : 5 Agustus 2018, disetujui: 12 Januari 2019

\section{PENDAHULUAN}

Pemakaian pupuk anorganik secara berlebihan dalam bidang pertanian dan secara terus menerus dapat mencemari lingkungan. Disatu sisi harga pupuk an organik semakin hari semakin mahal dan disisi lain diperlukan adanya peningkatan produksi pertanian guna memenuhi kebutuhan pangan masyarakat. Tingkat konsumsi pupuk anorganik juga semakin tinggi sementara bahan baku pupuk semakin menipis.

Pupuk anorganik yang digunakan untuk meningkatkan produksi pangan berdampak negative terhadap kesehatan. Penggunaan pupuk organic sebagai alternative dari dampak tersebut bermanfaat bagi tanaman, dan dapat memberdayakan tanah menjadi lebih baik 
untuk proses budidaya tanaman. Pupuk organic yang digunakan diupayakan dapat menekan penggunaan pupuk anorganik dan tidak merusak lingkungan. Tumbuhan yang dapat digunakan menjadi pupuk organic yang dapat dimanfaatkan sebagai sumber N salah satunya Azolla pinnata.

Penggunaan pupuk organik yang berasal dari bahan organik merupakan alternative tepat yang dapat dilakukan untuk mengurangi dampak penggunaan pupuk kimia. Pupuk organik dapat dibedakan atas pupuk organik padat dan pupuk organik cair. Pupuk organik cair meskipun mengandung unsur hara yang rendah tetapi memiliki kelebihan di bandingkan dengan pupuk padat, karena penyerapan unsur hara lebih cepat diserap tanaman. Salah satu POC yang dapat di manfaatkan dan memiliki unsur hara nitrogen yang tinggi adalah POC Azolla microphylla. Sedangkan pupuk organik padat seperti kompos Azolla microphylla berperan pada sifat fisik tanah terutama struktur tanah, dimana peran ini tidak bisa digantikan dengan pupuk yang lain.

Azolla yang digunakan pada budidaya tanaman padi, berperan sebagai pupuk organic dalam menyediakan unsur $\mathrm{N}$, hal ini disebabkan karena Azolla memiliki Cyanobacteria. Simbiosis anatara keduanya disebut dengan Anabaena azollae yang dapat menfiksasi N bebas di udara dan dapat digunakan oleh tanaman melalui penyerapan oleh akar tanaman Sudjana, 2014)

Penelitian yang dilakukan oleh Supartono, Widyasumu, Rusdiyanto, dan Santoso (2012) menyimpulkan bahwa Azolla sangat potensial dikembangkan sebagai pupuk dan pakan ternak, perkembangannya sangat cepat, dari 1 ton hektar $^{-1}$ inokulasi menjadi 11,48 $-21,68$ ton hektar ${ }^{-1}$ dalam waktu 24 hari.

Rahmawati dan Widyasunu (2013) melaporkan bahwa pupuk bokashi berbahan dasar Azolla microphylla dan Lemmna polirhyza. Dapat meningkatkan serapan $\mathrm{N}$ tanaman sampai $669 \%$ dengan menggunakan pupuk dan 512\% pada tanaman tanpa menggunakan pupuk (control), sekaligus meningkatkan hasil $263,89 \%$ pada tanaman yang diberi pupuk dan 267,89\% pada tanaman tanpa pemupukan. Hasil penelitian Arafah, Setiawati, dan Nurbaity (2017) bahwa pemberian Azolla pinnata pada budidaya padi pada tanah dengan salinitas tinggi yaitu 6 mmhos $\mathrm{cm}^{-1}$ dapata meningkatkan serapan $\mathrm{N}$, dan pemberian Azolla pinnata berpengaruh terhadap bobot kering tanaman padi.

Pada penelitian dengan kombinasi $50 \%$ pupuk $\mathrm{N}+50 \%$ Azolla segar, dan $25 \%+75 \%$ Azolla segar memperlihatkan hasil padi ton hektar ${ }^{-1}$ lebih baik bila dibandingkan dengan pemberian N 100\% (Soedharmo, Tyasmoro, dan Sebayang, 2016). Huda, Widaryanto, dan Nugroho (2016) melaporkan bahwa tanaman wortel varietas kuroda yang diberi 5 ton hektar ${ }^{-1}$ Azolla menhasilkan umbi 34,09 ton hektar 1. Hasil hasil penelitian yang sudah dilakukan tersebut menjadi acuan untuk melakukan penelitian dengan menguji komposisi kimia yang terkandung di dalam kompos Azolla. Tujuan penelitian ini untuk mendapatkan komposisi kimia kompos dan POC Azolla microphylla.

\section{METODE PENELITIAN}

Penelitian dilakukan di lahan percobaan Fakultas Pertanian Universitas Lancang Kuning, yang dimulai pada bula Februari sampai dengan Maret 2018. Ketinggian tempat 20 meter dpl.
Bahan-bahan yang digunakan dalam penelitian ini adalah Azolla, dedak, molase, air, gula merah, dan EM-4. Peralatan yang digunakan untuk mendukung penelitian ini adalah alat 
pencacah, drum, komposter, ember, Kompos azolla yang sudah matang blender, gelas ukur, hand sprayer, dan kemudian dikeringanginkan guna pengaduk.

Pengujian komposisi kimia kompos dan POC dilakukan di Laboratorium, dan yang ingin diketahui dari komposisi kimia kompos azolla adalah:

Tabel 1. Komposisi Kimia Kompos azolla yang diuji

\begin{tabular}{|c|c|c|}
\hline No & Parameter Uji & Satuan \\
\hline 1. & $\mathrm{pH} \mathrm{H}_{2} \mathrm{O}$ & - \\
\hline 2. & C-organik & $\%$ \\
\hline 3. & N-total & $\%$ \\
\hline 4. & C/N Ratio & - \\
\hline 5. & $\mathrm{P}_{2} \mathrm{O}_{5}$ - total & $\%$ \\
\hline 6. & $\mathrm{~K}_{2} \mathrm{O}$ - total & $\%$ \\
\hline 7. & Ca- total & $\%$ \\
\hline 8. & $\mathrm{Mg}$ - total & $\%$ \\
\hline 9. & S- total & ppm \\
\hline 10. & Mn- total & ppm \\
\hline 11. & $\mathrm{Cu}$ - total & ppm \\
\hline 12. & Zn- total & ppm \\
\hline 13. & B- total & $\mathrm{ppm}$ \\
\hline 14. & KTK & $\mathrm{cmol}(+) / \mathrm{kg}$ \\
\hline 15. & K-dd & $\mathrm{cmol}(+) / \mathrm{kg}$ \\
\hline 16. & Na-dd & $\mathrm{cmol}(+) / \mathrm{kg}$ \\
\hline 17. & Ca-dd & $\mathrm{cmol}(+) / \mathrm{kg}$ \\
\hline 18. & Mg-dd & $\mathrm{cmol}(+) / \mathrm{kg}$ \\
\hline 19. & $\mathrm{Cl}$ & \\
\hline
\end{tabular}

\section{Pembuatan Kompos Azolla}

Wadah drum

disiapkan, selanjutnya cacah tumbuhan azolla menjadi bagian kecil-kecil, Taburkan dedak pada cacahan azolla dengan merata, campurkan decomposer dan molase dengan air dalam satu botol (35\% EM-4 molase $15 \%$ dan air $50 \%$ aduk lalu semprotkan hingga basah), biarkan selama 12 - 15 hari dengan tetap menjaga kelembaban kompos dan mengaduk kompos agar terjadi penguraian secara merata. Kompos azolla dapat dipanen dan diangin-anginkan terlebih dahulu untuk mengurangi kelembaban kompos. mempermudah dalam pengangkutan, dan analisa kimia.

Tabel 2. Komposisi POC Azolla yang ingin akan diuji

\begin{tabular}{|c|c|c|}
\hline No & Parameter Uji & Satuan \\
\hline 1. & $\mathrm{pH} \mathrm{H} \mathrm{H}_{2} \mathrm{O}$ & - \\
\hline 2. & C-organik & $\%$ \\
\hline 3. & N-total & $\%$ \\
\hline 4. & $\mathrm{P}_{2} \mathrm{O}_{5}$ - total & $\%$ \\
\hline 5. & $\mathrm{~K}_{2} \mathrm{O}$ - total & $\%$ \\
\hline 6. & $\mathrm{Ca}-$ total & $\%$ \\
\hline 7. & Mg- total & $\%$ \\
\hline 8. & S- total & ppm \\
\hline 9. & Mn- total & ppm \\
\hline 10. & $\mathrm{Cu}$ - total & ppm \\
\hline 11. & Zn- total & ppm \\
\hline 12. & B- total & ppm \\
\hline 13. & $\mathrm{Cl}$ & $\%$ \\
\hline
\end{tabular}

\section{Pembuatan POC Azolla mycrophylla.}

Wadah ember disiapkan, selanjutnya azolla di blender sampai halus, dan campurkan Azolla microphylla halus, gula merah, air, dan $\mathrm{EM}_{4}$ (10cc). Semua bahan dicampur jadi satu dan masukkan ke ember. Tutup rapat. Diamkan selama 2 seminggu (7 -14 hari) hingga aromanya seperti aroma tape, lalu POC sudah bisa dipanen. Setiap hari tutup botol dibuka untuk melepaskan gas fermentasi. Untuk memanen POC, saring cairannya dan simpan dalam botol terpisah. Sementara untuk ampas Azollanya, bisa dicampurkan ke komposter untuk membuat kompos Azolla atau bisa juga diangin-anginkan untuk ditebar ke media tanam sebagai pupuk padat.

Analisis data dilakukan dengan menggunakan analisis sekriptif kualitatif berdasarkan hasil uji laboratorium terhadap komposisi kimia kompos berbahan dasar azolla. 


\section{HASIL DAN PEMBAHASAN}

Azolla sangat prospektif untuk mendukung pertanian organik. Azolla dengan berbagai keuntungan dan kelebihan dengan pengaplikasian Azolla hal ini bisa menjadi salah satu alternative pupuk organik yang dapat berkombinasi dengan pupuk $\mathrm{N}$ anorganik dalam mengefisiensi pupuk an organik khususnya urea. Azolla dapat diaplikasikan dari berbagai bentuk Azolla mycrophylla (kompos, POC, ekstrak, azolla basah dan azolla kering) untuk dapat mengefisiensikan atau mengurangi pemakaian pupuk urea. Hasil analisis kompos Azolla mycrophylla dan POC Azolla mycrophylla telah memenuhi standard pupuk organik menurut Permentan No.28 tahun 2009.

Bank Azolla yang dapat dibuat dari bak-bak kayu atau ember-ember merupakan salah satu upaya rekayasa sosial-budaya petani sebagai center (pusat) transformasi teknologi. Hal ini sebagai upaya penyediaan bahan baku lokal sebagai upaya pengembangan potensi daerah (local genious). Suatu hal yang mustahil bila suatu penerapan teknologi dapat teraplikasi dengan baik pada masyarakat jika bahan baku itu sendiri tidak tersedia pada daerah tersebut atau bahkan sulit untuk mendapatkannya. Dengan berbagai keuntungan dan kelebihan dengan pengaplikasian Azolla hal ini bisa menjadi salah satu alternative pupuk organik yang dapat berkombinasi dengan pupuk $\mathrm{N}$ anorganik dalam mengefisiensi pupuk an organik khususnya urea. Azolla juga dapat digunakan dalam berbagai bentuk seperti Azolla segar,
Azolla kering, Pupuk Organik Cair, dan kompos. Untuk itu Azolla mycrophylla layak untuk dijadikan agen pen-fiksasi N. Azolla biasanya hidup bergerombol dalam jumlah banyak diatas permukaan air. Pertumbuhan Azolla sangat cepat dan melimpah jumlahnya, hanya saja tanaman Azolla ini belum begitu familiar dikenal petani khususnya petani Riau untuk itu perlu pengembangan bank Azolla yang sangat penting sebagai infrastruktur konservasi biomassa hidup azolla.

Hasil analisa menunjukkan bahwa aplikasi azolla dapat meningkatkan kesuburan tanah. Analisis kimia yang telah dilakukan terhadap kompos Azolla mycrophylla menunjukkan bahwa $\mathrm{pH}$ yang dihasilkan tinggi yaitu 6,5 dan tergolong mendekati netral berdasarkan kriteria penilaian sifat-sifat kimia tanah Pusat Penelitian Tanah (1983), dengan Corganik $42,95 \%$ termasuk dalam kriteria sangat tinggi. $\mathrm{N}$ total $3,94 \%$ termasuk sangat tinggi, hasil analisis ini juga sesuai dengan hasil analisis Laboratorium Bioteknologi Pertanian UMM (2003) yang mana Azolla pinnata mengandung N 2,55 $3,95 \%$. Sedangkan untuk rasio $\mathrm{C} / \mathrm{N} 11$ mengindikasikan bahwa kompos Azolla mycrophylla dalam kondisi cukup baik (kriteria sedang) dalam memasok hara yang dibutuhkan tanaman. $\mathrm{C} / \mathrm{N}$ ratio menunjukkan tingkat dekomposisi dari suatu bahan organic yang dikomposkan, bila $\mathrm{C} / \mathrm{N}$ ratio rendah berarti bahan organic sudah terurai, sedangakan bila $\mathrm{C} / \mathrm{N}$ ratio tinggi maka dekomposisi belum sempurna (Hakim, et al. 1986). 
Tabel 3. Hasil Analisis Kimia Kompos dan POC Azolla mycrophylla

\begin{tabular}{cllcc}
\hline No & Parameter Uji & & Satuan & \multicolumn{2}{c}{ Azolla mycrophylla } \\
\cline { 3 - 5 } & & - & Kompos & POC \\
\hline 1. & $\mathrm{pH} \mathrm{H} \mathrm{H}_{2} \mathrm{O}$ & $\%$ & 4,5 & 4,3 \\
2. & $\mathrm{C}-$-organik & $\%$ & 3,95 & 0,10 \\
3. & $\mathrm{~N}-$ total & - & 11 & 0,05 \\
4. & $\mathrm{C} / \mathrm{N}$ Ratio & $\%$ & 1,21 & - \\
5. & $\mathrm{P}_{2} \mathrm{O}_{5}$-total & $\%$ & 4,88 & 0,02 \\
6. & $\mathrm{~K}_{2} \mathrm{O}-$ total & $\%$ & 0,95 & 1,54 \\
7. & $\mathrm{Ca}-$ total & $\mathrm{ppm}$ & 0,57 & 0,04 \\
8. & $\mathrm{Mg}$ - total & $\mathrm{ppm}$ & 0,24 & 16 \\
9. & $\mathrm{~S}-$ total & $\mathrm{ppm}$ & 542 & 55 \\
10. & $\mathrm{Mn}$ - total & $\mathrm{ppm}$ & 6 & 0,8 \\
11. & $\mathrm{Cu}-$ total & $\mathrm{ppm}$ & 46 & 5,9 \\
12. & $\mathrm{Zn}-$ total & $\mathrm{cmol}(+) / \mathrm{kg}$ & 55 & 1,6 \\
13. & $\mathrm{~B}-$ total & $\mathrm{cmol}(+) / \mathrm{kg}$ & 7,41 & - \\
14. & $\mathrm{KTK}$ & $\mathrm{cmol}(+) / \mathrm{kg}$ & 16,11 & - \\
15. & $\mathrm{~K}-\mathrm{dd}$ & $\mathrm{cmol}(+) / \mathrm{kg}$ & 1,23 & - \\
16. & $\mathrm{Na}-\mathrm{dd}$ & $\mathrm{cmol}(+) / \mathrm{kg}$ & 1,10 & - \\
17. & $\mathrm{Ca}-\mathrm{dd}$ & $\%$ & 2,04 & - \\
18. & $\mathrm{Mg}-\mathrm{dd}$ & $\mathrm{Cl}$ & 0,14 & 0,04 \\
\hline
\end{tabular}

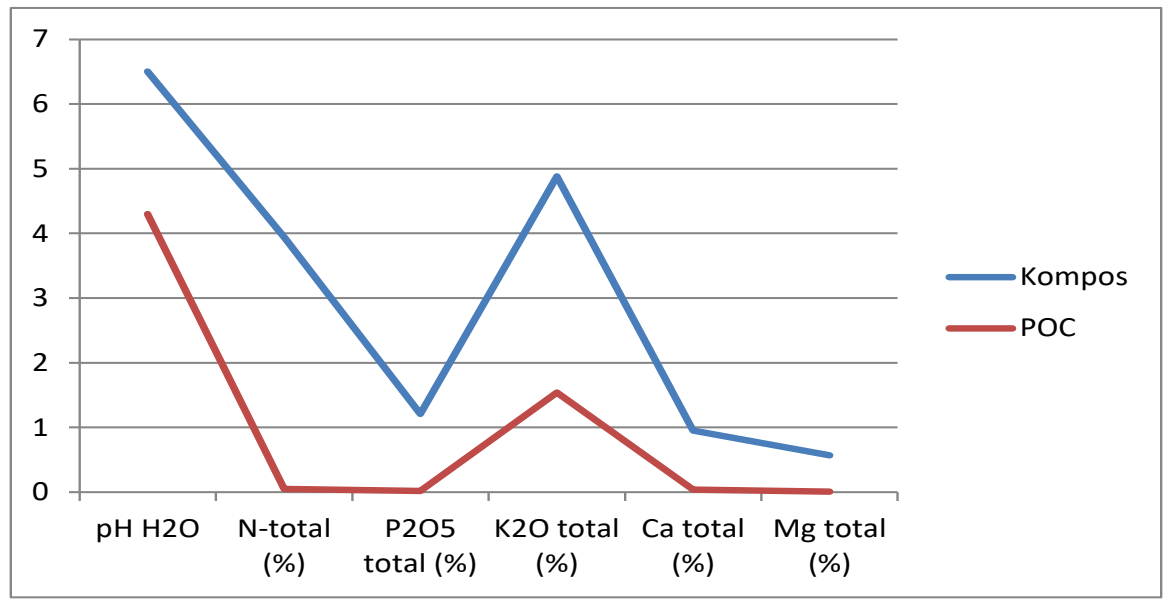

Gambar 1. Grafik Perbandingan pH, N,P,K,Ca dan Mg Kompos Azolla mycrophylla dan POC Azolla mycrophylla

Gambar 1. menunjukkan bahwa kadar nitrogen $(\mathrm{N})$ dalam bahan kompos kandungan hara khususnya N,P,K,Ca dan harus lebih tinggi dari nilai kritisnya yaitu $\mathrm{Mg}$ kompos Azolla mycrophylla lebih antara 1,5\%-2,5\%. Lebih lanjut Janzen tinggi dibandingkan POC Azolla dan Kucey (1988) dalam Wahyudi (2009) mycrophylla. "Berdasarkan hasil tersebut mengemukakan bahwa nilai kritis kadar diatas dapat diketahui bahwa kandungan nitrogen $(\mathrm{N})$ adalah sekitar 1,9 \% - 1,1\%, nitrogen $(\mathrm{N})$ pada kompos azolla masih bila kadar $\mathrm{N}$ berada di bawah nilai kritis berada diatas nilai kritisnya sehingga dapat tersebut maka akan terjadi immobilisasi". segera termineralisasi. Menurut Stevenson Komposisi kimia kompos Azolla (1994) dalam Isrun (2010) bahwa agar mycrophylla $\mathrm{P}_{2} \mathrm{O}_{5}-$ total $1,21 \%, \mathrm{~K}_{2} \mathrm{O}-$ segera dapat terjadi mineralisasi maka total $4,88 \%$ hal ini tidak berbeda dengan 
analisis kimia azolla kering yaitu bila ditinjau dari analisis kimia azolla kering (Puspita et al, 2016) bahwa azolla kering mengandung unsur N 3- 5\%, P 0,5-0,9\% dan K $2-4,5 \%$

"Penetapan kandungan bahan organik dilakukan berdasarkan jumlah Corganik. C-Organik (bahan organik) merupakan semua jenis senyawa organik yang terdapat di dalam tanah, termasuk serasah, fraksi bahan organik ringan, biomassa mikroorganisme, bahan organik terlarut di dalam air, dan bahan organik yang stabil atau humus. Kandungan Corganik merupakan pembeda dengan pupuk an organik. POC Azolla mycrophylla hasil analisis C-organik $0,10 \%$ sedangkan standard dari Permentan, 2009 pupuk organik kandungan C-organik

\section{KESIMPULAN}

Hasil penelitian analisis kimia kompos Azolla mycrophylla dan POC Azolla mycrophylla dapat disimpulkan bahwa pH kompos Azolla mycrophylla 6,5 lebih tinggi dari pada $\mathrm{pH}$ POC Azolla mycrophylla 4.3, kandungan N,P,K,Ca dan

\section{DAFTAR PUSTAKA}

Amir, L., Sari, A. P., Hiola, S. F., dan Jumadi, O., 2012. Ketersediaan Nitrogen Tanah dan Pertumbuhan Tanaman Bayam (Amaranthus tricolor L.) yang Diperlakukan dengan Pemberian Pupuk Kompos Azolla. Jurnal Sainsmat, Vol. 1(2):167-180

Arafah, M.S,. , Setiawati, M.R., Nurbaity, A., 2017. Pengaruh Pupuk Organik (Azolla pinnata) Terhadap C-Organik Tanah, Serapan N Dan Bobot Kering Tanaman Padi (Oryza sativa L.) Pada Tanah $\geq 4 \%$. Bila C-organik rendah dan tidak masuk dalam ketentuan standard Permentan, 2009 maka diklasifikasikan sebagai pembenah tanah (soil ameliorant )". Rendahnya C-organik pada POC Azolla mycrophylla berperan rendah sebagai bahan/pupuk organik yang berperan memperbaiki sifat fisik tanah yaitu sebagai pengikat butiran primer menjadi butir sekunder tanah untuk membentuk agregat yang mantap yang akan mempengaruhi pori tanah, reservoir air, tata udara tanah, dan suhu tanah, POC lebih kepada manfaat dari segi kimia. Kompos azolla yang sudah matang dan diaplikasikan pada tanah mempengaruhi secara nyata kadar ammonium dan nitrat tanah, dan berpengaruh terhadap kadar nitrat air lindi (Amir, Sari, Hiola, dan Jumadi, 2012).

Mg kompos Azolla mycrophylla lebih tinggi dari POC Azolla mycrophylla, hasil analisis kompos Azolla mycrophylla dan POC Azolla mycrophylla telah memenuhi standard pupuk organik menurut Permentan No.28 tahun 2009.

Dengan Tingkat Salinitas Tinggi. Jurnal Untirta: 1-12

Gunawan,I. 2014. Kajian Peningkatan Peran Azolla Sebagai Pupuk Organik Kaya Nitrogen Pada Padi Sawah. Jurnal Penelitian Pertanian Terapan. Vo. 14 (2).

Hakim.N, Y.Nyakpa, Lubis, Nugroho.S.G, Diha.A, Go Ban Hong, Bailey, 1986. Dasar-Dasar Ilmu Tanah. Unila Press

Huda,MS, Widaryanto,E, dan Nugroho,A. 2016. Pengaruh Beberapa Dosis 
Kompos dan Azolla (Azolla pinnata) Segar pada Pertumbuhan dan Hasil 2 Varietas Tanaman Wortel (Daucus carotta L). Jurnal Produksi Tanaman. Vol 4 (6): 431437.

Isrun, 2010. Perubahan Serapan Nitrogen

Tanaman Jagung dan Kadar Al-dd Akibat Pemberian Kompos Tanaman Legum dan Nonlegum Pada Inseptisols Napu. J.Agroland 17 (1).

Nurmayulis, Utama,P, Firnia,D, Yani,H dan Citraresmini,A.2011. Respon Nitrogen dan Azolla Terhadap Pertumbuhan Tanaman Padi Varietas Mira I dengan Metode SRI. Jurnal Ilmiah Aplikasi Isotop dan Radiasi Vol.7 (2).

Rahmawati, E., dan , Widyasunu, P., 2013 - Pengaruh Bokashi Berbasis Azolla microphylla Dan Lemna polyrhiza Terhadap Serapan N Dan Produksi Tanaman Pakchoy (Brassica chinensis L.), Serta Porositas Inseptisols. . Jurnal Agrin, Vol $17 \quad$ (2):81-91. DOI: http://dx.doi.org/10.20884/1. agrin.2013.17.2.201.
Soedharmo,GG, Tyasmoro,SY, dan Sebayang,T.2016. Pengaruh Pemberian Pupuk Azolla dan Pupuk N pada Tanaman Padi (Oryza sativa) Varietas Inpari 13. Jurnal Produksi Tanaman Vol.4 (2): $145-152$

Sudjana, B., 2014. Pengunaan Azolla Untuk Pertanian Berkelanjutan. Jurnal Ilmiah Solusi, Vol. 1(2): 7281.

Supartoto, Widyasunu, P., Rusdiyanto dan Santoso, M., 2012. Eksplorasi Potensi Azolla microphylla dan Lemna Polyrhizza Sebagai Produsen Biomas Bahan Pupuk Hijau, Pakan Itik Dan Ikan. Prosiding Seminar Nasional , Pengembangan Sumber Daya Pedesaan dan Kearifan Lokal Berkelanjutan II. Purwokwrto: 217-225.

Wahyudi, L. 2009. Manfaat Bahan Organik Terhadap Peningkatan Ketersediaan Fosfor dan Penurunan Toksisitas Aluminium di Ultisol. Disertasi Program Pascasarjana Fakultas Pertanian Universitas Brawijaya, Malang. 